\title{
Characteristics of piezometric heads and determination of fresh water-salt water interface in the coastal zone near Beihai, China
}

\author{
Zhou Xun $\cdot$ Zhou Haiyan $\cdot$ Zhang Li
}

Published online: 12 December 2007

(C) Springer-Verlag 2007

\section{Erratum to: Environ Geol}

\section{DOI 10.1007/s00254-007-0793-8}

In the Introduction, the following sentence is missing before the last one:

Izuka and Gingerich (1998) presented a method to estimate the interface depth based on vertical head gradients using water-level measurements during drilling of a partially penetrating well above the interface. Effort was made by Kim et al. (in review, 2007) to estimate the interface depth using two sets of pressure data obtained from fresh and salt water zones respectively from a single borehole.
The sentence before Equation 1 should read:

At point $\mathrm{A}$, the following relation can be established when the subsurface flow system is nearly horizontal and in an equilibrium state:

The following reference should be added to the reference list:

Izuka SK, Gingerich SB (1998) Estimation of the depth to the fresh-water/salt-water interface from vertical head gradients in wells in coastal and island aquifers. Hydrogeol J 6:365-373 